\title{
$\operatorname{arCOS} D E S I G N$
}

\section{O papel do designer contemporâneo a partir das contribuições europeias na formação do profissional}

Edna Martins (UNESP, Brasil)

martinnsedna@yahoo.com.br

Programa de pós-graduação em Design - FAAC, Bauru, SP

Av. Eng. Luiz Edmundo Carrijo Coube, 14-01, CEP: 17033-360

Carolina Vaitiekunas Pizarro (UNESP, Brasil)

caroldipp@gmail.com

José Carlos Plácido da Silva (UNESP, Brasil)

placido@faac.unesp.br

Luis Carlos Paschoarelli (UNESP, Brasil)

paschoarelli@faac.unesp.br 


\title{
O papel do designer contemporâneo a partir das contribuições europeias na formação do profissional
}

Resumo: O presente artigo apresenta uma reflexão acerca da profissão de designer a partir do recorte histórico referente ao período pré-revolução industrial abordando a figura do desenhista industrial na França e enfatiza a atenção especial que lhe foi conferida na Inglaterra como foco da Revolução Industrial. Versa sobre algumas das mudanças que o design sofreu ao longo do tempo, mudanças estas que se dão em paralelo às transformações sociais, econômicas, tecnológicas. Este estudo também tece considerações sobre o papel do profissional na contemporaneidade e os desafios que se colocam à profissão.

Palavras chave: Design, Designer, Profissão

\section{The role of contemporary designer from the European contributions on the professional education}

\begin{abstract}
This article presents a reflection on the profession of designer from the historical period for the pre-industrial revolution approaching the figure of the industrial designer in France and emphasizes the special attention given to it in England as the focus of the Industrial Revolution. Deals with some of the changes that the designer profession suffered along the way, that these changes occur in parallel to social, economic, technological. This study also reflects on the role of the professional in contemporary society and the challenges facing the profession.
\end{abstract}

Key words: Design, Designer, Profession 


\section{Introdução}

A partir do sonho de Walter Gropius cristalizado na escola de artes alemã Bauhaus constitui-se a formação de um profissional capacitado e atento às diferentes etapas de um projeto, considerando aspectos artísticos, de construção e viabilidade. Embora a Bauhaus tenha tido uma breve trajetória, é inegável sua contribuição em termos de produção de um design moderno, mas foi na institucionalização do ensino da profissão e na formação acadêmica dos primeiros profissionais que a escola deixou seu principal legado, não significando, contudo que o profissional designer tenha surgido ali, no início do século XX.

O surgimento do profissional projetista - mais tarde denominado designer - é muito discutido e amplamente pesquisado, visto que em diferentes épocas e em diversas sociedades o ser humano desde os tempos mais remotos interage e modifica o ambiente. Assim, precisar sua origem torna-se uma tarefa complexa a qual demandaria muitas mais pesquisas e considerações do que as possíveis de serem abordadas neste breve estudo. Desta forma, o presente trabalho toma como ponto de partida para a reflexão sobre o papel do designer, o estudo de caso do desenvolvimento da profissão ocorrido especificamente na Europa, em período pré-revolução industrial.

Àquela época merece destaque a figura de Charles Le Brun, o qual possuía como uma de suas atribuições à função de inventeur ou criador de formas a serem produzidas na manufatura real de Gobelins, fundada na França em 1667. Mais tarde, a identidade do projetista se fortalece com a Revolução Industrial, cujo foco de desenvolvimento se deu na Inglaterra. Foi na era marcada pela produção de Josiah Wedgwood que o futuro profissional de design começa a se direcionar em diferentes vertentes com a afirmação de diferentes especificidades como o design gráfico, com o desenvolvimento de peças gráficas destinadas ao aumento de vendas, promoção de eventos bem como a construção de livros padrões de formas e medidas.

No início, quando se destacava principalmente como personagem importante no âmbito técnico e industrial, o designer começou a ser visto sob novos olhares dos empresários industriais, os quais enxergavam no profissional parte importante no processo de comunicação entre indústria e usuário.

Especificamente abordando o período, a produção e as criações na indústria de cerâmica de Wedgwood, o designer assume outros valores entre eles o de parte essencial do processo de produção, oferecendo vantagens como maior aceitação comercial, resultando em aumento de vendas e centralização das etapas decisivas do projeto.

O campo do design historicamente acompanha as transformações da sociedade, uma vez que produz a partir dos desejos e necessidades humanas, 
sendo o ser humano e suas interações o objetivo final de todo projeto. Na busca por compreender melhor a sociedade na qual se insere para assim produzir mais e melhor, áreas tangentes a um projeto de design - como, por exemplo, o design e a moda - aproximaram-se ainda mais visando o aprimoramento de projetos e interdisciplinaridade, sendo o campo da moda um difusor de tendências sociais. Entretanto cabe destacar que tal aproximação não é exclusiva da contemporaneidade, uma vez que a relação entre áreas ocorre desde os tempos iniciais do desenvolvimento industrial. Como criadores e desenvolvedores dos mais variados objetos de uso, os designers e sua produção sofreram modificações ao longo do tempo refletindo a época na qual estavam inseridos, influenciando-a e sendo ao mesmo tempo influenciados por ela, passando por alternâncias de diretrizes projetuais como aquelas relacionadas ás funções práticas, estéticas e simbólicas, que vão se movimentando e se adaptando conforme se movimentam e se modificam as necessidades de diferentes épocas.

Assim, a profissão desenvolveu-se, aprimorando-se até os dias atuais em um movimento contínuo, enfrentado desafios, tais como o reconhecimento do design como um campo de grande valor social, a questão da regulamentação da profissão, a dissociação da ideia de do design como um mero adorno de luxo e não de necessidade social. Porém, apesar destes grandes obstáculos o design tem avançado e se distanciado da ideia inicial de uma profissão puramente resultante de necessidade técnica-industrial.

\section{Profissionais projetistas na europa}

\subsection{O inventeur francês}

Com a implantação do sistema mercantilista, as diferentes nações envolvidas neste processo, se direcionaram, naturalmente, á uma disputa acirrada por mercados estrangeiros. Os estados começam a perceber a necessidade, cada vez maior, de investir na produção de bens de consumo, pois os governos estavam diretamente envolvidos com os meios de produção e, portanto ansiosos pelos resultados que poderiam surgir dessa relação político-econômica.

Quase todos os países europeus fundaram nos séculos XVII e XVIII, manufaturas reais, ou da coroa, para a fabricação de determinados tipos de produtos, principalmente artigos considerados de luxo como louças, têxteis e móveis. (CARDOSO, 2004, p. 20).

Diante das novas necessidades que surgiram oriundas de transformações sociais e econômicas, segundo Cardoso (2004) foi implantada na França, em 1667, sob o reinado de Luís XIV, a fábrica de Gobelins - sistema de manufaturas reais de móveis da coroa - sob o comando de Jean-Baptist Colbert. Numa organização bem sucedida, Colbert criou um polo de oficinas responsáveis 
pela fabricação de móveis reais, numa produção racionalizada. Tais instalações empregavam centenas de artesãos. Na referida fábrica havia a posição do inventeur - criador de formas a serem fabricadas - ocupadas por Charles Le Brun, o qual também ocupava o cargo de diretor. A ele era dada a incumbência de criar objetos e gerar seus desenhos, os quais serviriam de base para a produção de peças em diferentes materiais executadas pelos mestres artesãos em suas oficinas. De modo sucinto, ao inventeur cabia o projeto, enquanto ao mestre-artesão cabia a execução (BOWMAN apud CARDOSO, 2004). Nesta época já se percebe uma clara dissociação entre projeto e produção.

Outro acontecimento que merece destaque ocorreu na Inglaterra, na década de 1750, em Staffordshire: a fundação da empresa de Josiah Wedgwood. Suas atividades manufatureiras se baseavam na produção de cerâmicas, inicialmente empregando cerca de vinte trabalhadores, em aproximadamente duas décadas transformou-se em uma indústria de porte internacional, exportando para a Europa e para as Américas, com representantes em Dublin e em Londres. Essa transformação da Wedgwood foi consequência de fatores que englobavam o design entre seus agentes de processo produtivo (CARDOso, 2004). O designer começa a atentar ao mercado público observando suas necessidades e aspirações.

\subsection{Os diferentes designs ingleses: Wedgwood}

Foco de desenvolvimento e inovação de produtos, a Josiah Wedgwood pode ser vista como um centro onde se manifestaram diferentes áreas do design, como o design de produto e o design gráfico, além de uma das primeiras empresas a empregar o designer como profissional responsável pelo projeto. $\mathrm{Na}$ Wedgwood surgiram novos produtos, novos materiais, novas formas de marketing. Mais uma vez o impulso dessas transformações deu-se por mudanças no âmbito social, econômico e tecnológico.

No que tange a atenção a novos mercados e públicos como base para o desenvolvimento do design, Wedgwood não se comportou de forma diferente. Segundo Cardoso (2004), ele observava o crescente mercado de classe média, o qual manifestava o desejo de possuir louças de boa qualidade, porém sem as condições financeiras necessárias para a aquisição de louças de procedência chinesa ou os produtos de valores mais altos produzidos em Meissen ou Sèvres. Para atender esse público alvo, nascia à necessidade de desenvolver um novo material - neste caso um novo tipo de louça - cuja aparência fosse semelhante á da porcelana, mas com um preço compatível ás condições financeiras oferecidas por esse novo consumidor que surgia. Em 1760 surgia a creamware - um tipo de cerâmica esmaltada adequada à moldagem em grande escala (CARDOSO, 2004); mais tarde rebatizada como queensware. 
A demanda por artigos de cerâmica aumentou constantemente durante o século XVII, mas não apenas devido ao crescimento da população a nova popularidade do chá requeria taças de cerâmica (uma vez que não é possível beber líquidos quentes com conforto num recipiente de metal), ao mesmo tempo em que a expansão colonial criava mercados no além-mar. Esses desdobramentos beneficiavam a indústria como um todo e a maioria dos fabricantes aumentaram seu comércio. Mas Wedgwood foi o mais bem-sucedido. (FORTY, 2007, p. 28).

Em 1774 deu-se mais uma inovação técnica - o aperfeiçoamento de uma cerâmica chamada jasper. Uma cerâmica leve e passível de ser produzida em várias cores (CARDOSo, 2004). Também chamado "jaspe" este material era branco, levemente translúcido e detentor de uma textura semelhante à do mármore. Um material que mais tarde foi aperfeiçoado para o jaspe colorido e o "banho de jaspe" - um colorido de superfície para o jaspe branco. O jasper ou jaspe havia sido desenvolvido originalmente com a finalidade de proporcionar um material adequado à reprodução de gemas e camafeus antigos, porém, Josiah Wedgwood, na época associado a Thomas Bentley, queriam encontrar para o novo material outras aplicações comercias.

Percebendo que o jasper possuía um aspecto semelhante ao do mármore, eles solucionaram esta questão com a aplicação no crescente mercado de ornamentos neoclássicos - este material passou a ser empregado também em jarros e placas com desenhos moldados em relevo; Wedgwood passou a produzir tais objetos em padrões antigos. Havia também outros materiais como o "basalto negro", utilizado principalmente em estatuetas e urnas. De modo geral, estes produtos alcançaram grande sucesso e satisfizeram amplamente a demanda pela estética neoclássica (FORTY, 2007).

Atendo ás mudanças que ocorriam ao seu redor, Josiah Wedgwood se empenhava em desenvolver novos materiais, novos produtos, novas formas, sendo estas as diretrizes permanentes de projeto de produtos aplicadas até os dias atuais. Paralelamente, a expansão das atividades comerciais exigia divulgação mais ampla - investe-se em novas formas de marketing, publicidade e propaganda. Neste sentido começa a se destacar o design gráfico.

Wedgwood e Bentley se utilizavam de catálogos para divulgar seus produtos, valendo-se destes meios de comunicação para expor inclusive suas inovações técnicas - mesmo de maneira mais reservada -, chamando a atenção do público. Segundo Cardoso (2004), a venda por meio de catálogos foi uma inovação da Wedgwood, pois seus produtos eram oferecidos inclusive por meio de livros que exibiam uma seleção de formas e padrões, oferecendo ao consumidor a vantagem de adquirir o modelo desejado, e à fábrica a vantagem de não ficar com o estoque paralisado (FORTY apud CARDOso, 2004). 
A divulgação de produtos por meio de catálogos alcançou tanto reconhecimento que segundo consta em Heskett (2006), seis edições do catálogo Useful Ware (grifo do autor) foram publicadas em francês, alemão e holandês. A Wedgwood assumiu tamanha importância no design de seus produtos que ao ser reproduzida a cópia do Vaso Portland (1790), foi desenvolvido um ingresso exclusivo para o acesso ao lançamento da cópia do referido produto.

Ainda no que se refere ao design gráfico, é relevante destacar o desenvolvimento dos desenhos que seriam aplicados nos produtos por meio de decalques. Segundo Cardoso (2004), a aplicação por decalques de decorações pintadas foi outra inovação técnica que contribuiu para o sucesso das louças desenvolvidas pela Wedgwood. No início as decorações eram feitas pelos artistas e artesãos da fábrica, mas diante da insatisfação quanto à arte e pintura manifestada por Wedgwood, o processo de decoração tomou outro rumo, passando para a aplicação de decalques. Consta em Heskett (2006) que em 1752, Wedgwood contratou a firma Sadler e Green, de Liverpoll, para desenvolver padrões de acordo com suas especificações; a citada firma havia criado técnicas de transferência de impressão para a decoração em cerâmica. Além desta exigência de Wedgwood, o mesmo autor cita que foram compilados livros de padrões com desenhos de bordas e motivos decorativos e livros de formas, os quais traziam desenhos de formas e especificações de tamanhos.

Wedgwood, em determinados casos, se manifestou dando atenção à opinião do cliente como parte integrante do desenvolvimento do projeto. Ao tratar sobre muitos de seus primeiros produtos decorativos de estilo barroco, carregados de ornamentos e dourados na superfície, as mudanças efetuadas por Wedgwood resultaram de sugestões não só de Bentley, mas também de seus clientes. Assim, manifestava preocupações em oferecer ao usuário produtos que atendessem além de suas necessidades estéticas, também às necessidades voltadas à utilidade e durabilidade do produto. Assim relata Heskett (2006) ao comparar duas empresas da época:

Diversas características das firmas de Boulton e Wedgwood antecipavam futuras evoluções. [...] O de Boulton era de produtos decorativos para um mercado da moda cujo gosto mudava rápido; o de Wedgwood era de objetos domésticos nas quais a forma estética tinha que conciliar com exigências de utilidade e durabilidade (HESKETt, 2006, p. 18). A Wedgwood foi um importante centro de design, mesmo que assim não fosse desde o início, reconhecida.

Por iniciativa de Josiah Wedgwood, e mais tarde associado á Thomas Bentley, deu-se merecida atenção ao design de produto - desenvolvimento de novos materiais, formas, produtos -, ao design gráfico - atenção proporcionada á produtos impressos, desenhos -, ao marketing, publicidade, propaganda. Nas fábricas sob o comando de Wedgwood, atentou-se para a produção de 
produtos nos quais se consideravam as aspirações do público, e mesmo com inspiração no passado - como a produção de peças em estilo neoclássico eram aliados a novas tecnologias, sempre incorporando os avanços e aspirações da época.

\section{O papel do designer na produção}

Antes do advento de industrialização o processo de desenvolvimento de produtos se preocupava principalmente com as necessidades estéticas e simbólicas dos usuários, necessidades tão requisitadas entre os mais abastados. Os objetos eram impregnados de ornamentações, muitos deles inclusive utilitários domésticos, produzidos com a utilização de materiais caros. Tais produtos eram confeccionados principalmente por artesãos, o que resultava num processo de produção que exigia gastos ainda mais dispendiosos.

Com a Revolução Industrial, este quadro foi, aos poucos, se modificando. O processo de produção em série resultou em mudanças que ultrapassaram o âmbito da tecnologia. Começam a ganhar destaque outros tipos de profissionais, entre eles o designer, o qual adquire cada vez mais importância neste novo quadro que se formava. Se no início o designer assumia uma posição de importância principalmente técnica e industrial, ele foi paulatinamente incorporando outros valores e sendo visto sob novas perspectivas, entre elas assumindo o papel de mensageiro no processo de comunicação entre indústria e usuário. Assim se manifesta Landim (2010, p. 21):"O produto é o mediador entre a fabricação e o consumidor, e o seu design é que contém a mensagem”.

Mesmo na época das famosas Wedgwood e Etrúria, o designer já começava a ganhar mais espaço e importância. Um bom exemplo se deu entre Josiah Wedgwood e modeladores como Willian Greatbach e John Flaxman. Na década de 1750 , a modelagem além de ficar reconhecida como uma atividade dissociada da produção - apesar de ser feita por um artesão ou mestre oleiro da mesma fábrica - passou a ser produzida por indivíduos descritos como modeladores, cuja única tarefa era fazer protótipos para servirem de base a outro artífice (FORTY, 2007).

Os bons modeladores tornavam-se cada vez mais indispensáveis para Wedgwood à medida que se reduzia a liberdade dos artífices de controlar a forma dos produtos. Isso valia sobre tudo para a louça creme, cujo engenho estava todo voltado para obter uniformidade. $O$ valor do modelador na preparação de um design exato aumentava com o número de artigos feitos a partir dele, porque estava, em certo sentido, assumindo uma fração de trabalho que costumava ser feito pelos artesãos cada vez que confeccionavam uma cerâmica. (FORTY, 2007, p. 51). 
Conforme o mesmo autor, devido á importância atribuída a seus serviços, os modeladores eram os trabalhadores mais bem pagos das cerâmicas. O trabalho de design era realizado por modeladores em Etrúria, ou por artistas especificamente contratados, destacando-se John Flaxman. Os artesãos de

Wedgwood estavam capacitados a fazer cópias, porém, o valor de Flaxman sobressaia em sua apreciação ao espírito revival clássico e sua capacidade de dar um ar também clássico a novos produtos desprovidos de um equivalente antigo exato. Segundo Cardoso (2004), John Flaxman era desenhista e mais tarde se tornou escultor. Trabalhou para Josiah Wedgwood por quase duas décadas - como freelancer - produzindo em Londres e em Roma, desenhos para serem executadas em Etrúria (fundada em 1769), inicialmente voltadas á produção somente de vasos e outras peças decorativas. Wedgwood percebeu rapidamente as vantagens dessa despesa adicional, visto que o emprego de um profissional qualificado para elaborar um projeto garantia não somente que as peças tivessem maior aceitação comercial como também centralizava o controle sobre os aspectos mais decisivos do processo produtivo. (FORTY in CARDOSO, 2004, p. 23).

Em uma época na qual se iniciava a produção em larga escala, tornava-se importante a uniformização dos artigos, e enquanto Wedgwood não tomou a iniciativa de buscar padronizar sua produção, esta estaria sempre sujeita a variações nos objetos.

Essas inovações tiveram um efeito radical no processo do design. A precisão do molde repetido tirava o controle das mãos dos operários que executavam o serviço, colocando toda a responsabilidade pela qualidade nos designs do protótipo. Havia modeladores e designers habilidosos por toda parte e em 1775 Wedgwood tinha sete empregados em tempo integral, trabalhando com toda sua linha de produtos. (Heskett, 2006, p. 17).

Ainda no que se refere á importância de um profissional de design na elaboração de um protótipo na busca por eliminar a diferenciação na produção de objetos que deveriam se apresentar como padronizados, Forty (2007) declara: [...] a introdução do design como uma atividade de especialista foi global no desenvolvimento de todas as manufaturas, andando de mãos dadas com a divisão do trabalho. De outro modo, sem um conjunto de instruções para orientar o artesão, a manufatura de qualquer objeto teria toda a imprevisibilidade de um jogo, à medida que um homem após o outro acrescentasse seu trabalho ao produto. (FORTY, 2007, p. 53).

O designer já começava a assumir grande valor não só por questões técnicas, mas também por outras como de ordem ideológica. Ainda tomando como exemplo Wedgwood que inicialmente conduzia sua produção pautada no gosto neoclássico - há tempos gosto residente na mentalidade do povo 
contemporâneo -, sentiu a necessidade de sair em busca de profissionais mais envolvidos com a moda, pois o desejo do público começava a se modificar de modo que este estava finalmente se distanciando do neoclássico. Seus trabalhadores não possuíam repertório suficiente para 'imprimir' no produto aquilo que o povo buscava; que a moda exigia. Neste contexto Forty (2007, p. 53) relata: "os artesãos provincianos da classe trabalhadora ignoravam essas modas e Wedgwood foi obrigado a achar homens que tivessem contato com a alta sociedade e com o gosto dominante". Produtos desenvolvidos por conhecedores de moda e com repertório acadêmico começavam a ganhar posições de destaque. Empresários como Josiah Wedgwood pareciam prever o que aconteceria no futuro.

Dos tempos das fábricas de Wedgwood até os dias atuais, o designer como profissional foi constituindo seu caminho historicamente, produzindo a cultura material, alinhando-a as diferentes necessidades de diferentes épocas. $\mathrm{O}$ crescimento industrial galopante vislumbrado nos séculos posteriores, o surgimento do consumo de massa e o fortalecimento da mídia como ferramenta de acesso ao usuário aumentando a concorrência, forneceram as bases para o mercado atual global, no qual o designer atua com importância cada vez mais reconhecida - mesmo que ainda não de maneira ideal.

Gierke comentado por Willson (1999 apud MOTA; MARTINS; SILVA; NASCimento, 2007), descreve o design como um diferencial que vai além de um simples serviço, reconhecendo-a como uma das áreas de conhecimento técnico e científico, que colabora com estratégias de sobrevivência de uma empresa ou produto no mercado consumidor e competidor.

Outras empresas já acordaram para a importância do design em suas estratégias de posicionamento; empresas como a Honda, Nissan e Mazda, têm em seu corpo de executivos designers de formação, que trabalham nessas empresas precisamente nessa função (KESEL, 1999 in MOTA et al, 2007, p. 5).

O designer não se configura como um profissional pré-determinado a seguir um caminho livre de alterações, antes, sofre influências de âmbito social, tecnológico, ideológico, político, econômico.

\section{4. $O$ designer e a contemporaneidade}

O cenário que envolve o designer contemporâneo não se formou repentinamente, e talvez o vocábulo formado não seja o mais apropriado uma vez que a profissão continua se formando não sendo sobremaneira uma 'obra' acabada. No início da industrialização percebeu-se certa negligência quanto às características estéticas dos produtos, pois a produção em grande escala, num primeiro momento, não resultou em cuidados necessários quanto à aparência 
do produto. Este fato se deu, entre outros, porque, como tudo o que é novo, foi preciso uma adaptação de ordem social, tecnológica, política - a classe operária que se formava precisava de qualificação e novas habilidades para trabalhar em conjunto com as máquinas. Com as novas mudanças nos diferentes âmbitos da humanidade foram surgindo também novos campos profissionais, entre eles o design.

É relevante citar que o design contemporâneo possui características que o acompanham desde o passado, o novo é reflexo de sua história e de sua construção como processo histórico. Ao abordar o design contemporâneo, por vezes, pode-se transmitir a ideia equivocada de um rompimento com suas raízes, entretanto, certos aspectos permanecem, mesmo que tenham passado por modificações. Assim, o design e o próprio profissional do design configuram-se como partes de uma construção histórica e componentes de um processo muito maior que assimila, produz e transforma o entorno constantemente.

Já no século XVIII, o designer fazia de seus objetos, suportes para mensagens que queira transmitir. Neste aspecto relata Landim (2010, p. 22): "O design, como significado de comunicação, é capaz de converter tantos significados quantos formos capazes de transmitir". A partir do exemplo citado de Josiah Wedgwood é possível vislumbrar o início do que seria o referido papel que o designer também viria a representar.

Mesmo quando o designer começava configurando no produto a mensagem que o público gostaria de ver - seja pela visão inicial do neoclássico, seja pelos diferentes gostos que viriam surgir, motivados pela moda e mais tarde pelo marketing - esboçaram-se os primeiros laboratórios de pesquisa e atenção ao usuário, atitudes projetuais hoje consideradas essenciais como ferramentas não apenas de fomento à criação, mas de marketing e força das marcas, em um mercado global e altamente competitivo.

Neste mercado, o campo do design tem se expandido e se inter-relacionado a outras áreas afins - como a moda - assim como outros aspectos que acompanham o design desde séculos passados.

Desde o século XVIII, a sustentação dominante para o design tem sido o sistema de produção e consumo em massa, baseado na junção de forças da indústria e do comércio. Um dos temas ao qual o design é inevitavelmente ligado é o crescimento da economia capitalista. Está evidente na evolução do design e é parte integrante de seu desenvolvimento, assim como a divisão do trabalho, os objetos de desejo e as empreitadas empresariais para captação de novos mercados. Moda e design, por exemplo, têm estado intrinsecamente ligados desde há muito até os dias atuais. (LANDim, 2010, p. 22).

Traçando um breve paralelo entre identidades dos produtos na época de Wedgwood e da atualidade percebe-se que era nas mãos dos designers daquela 
época que residia o valor do design como transmissor de identidade à cultura material, valor este que é parte importante da profissão e essencial para o profissional até os dias atuais. No sentido de cunhar identidades à cultura material também se manifesta Landim (2010, p. 23) ao descrever: "Formamos nossas identidades, individuais e/ou coletivas, por meio das coisas que nos cercam, e os designers têm que levar também isto em conta".

Outra questão que merece destaque, porém, sob a ótica do contraste entre o design de épocas passadas e o design contemporâneo, é a ênfase que tem sido dada á questão da emoção e subjetividade no design. Em épocas passadas havia o predomínio da racionalidade nos projetos de design, priorizando a razão e a técnica. Contudo, mudanças ideológicas, pesquisas, inovações tecnológicas, e possibilidades de uso de novos materiais conduziram paulatinamente os projetos guiando-os para o caminho da emoção e subjetividade como parte importante no desenvolvimento de produtos, fatores que, portanto não podem ser desconsiderados. Atentos a estas mudanças, os designers criam no contemporâneo não apenas produtos, mas experiências de produtos, nos quais a funcionalidade começa a fundir-se com a significação, o emocional une-se à qualidade.

Segundo Mota (et al, 2007), a economia atual se encontra imersa em exagerada variedade de produtos com suas singularidades de fabricação e público alvo. Os produtos que compõem esta economia estão impregnados não só de características funcionais, mas também de características estéticas e simbólicas que intencionam satisfazer as necessidades psíquicas dos usuários.

Contudo podemos dizer que seria inviável a produção serial de produtos somente atendendo a quesitos prático funcionais, eles devem ser também projetados para um fim e propósito que assegure seu consumo e sejam rapidamente identificados e classificados pelos usuários por uma relação também emocional. (мота et al, 2007).

Há outras características que marca o design contemporâneo e que merecem destaque devido à sua importância além da funcionalidade, estética, simbolismo, moda, como a ergonomia, o poder de agregar valor econômico aos produtos e a sustentabilidade. O designer que timidamente foi ganhando destaque em meio a atividades ligadas á técnicas de produção, hoje se depara com maiores possibilidades de atuação, exemplificadas, segundo Löbach (2001), como: diretor de design, designer de sistemas de produtos, consultor em design, crítico em design, designer industrial como expert em planejamento e configuração do entorno, teórico do design, pedagogo do design.

$\mathrm{Na}$ atualidade, é das mãos destes habilidosos profissionais que surgem os mais variados produtos, com diversas finalidades. Cabe aos designers estarem atentos ao mundo que os cerca, analisando tendências, pesquisando novos 
materiais e viabilizando novas tecnologias, a fim de produzir produtos, experiências e inovações voltadas ao ser humano e suas necessidades - físicas, psíquicas e emocionais. Configurar o entorno contribuindo para o bem estar e a evolução da humanidade é o principal papel do designer.

\section{Desafios da profissão}

Um dos maiores desafios do design talvez tenha sido o reconhecimento como uma profissão de grande valor social. Sua história se construiu principalmente ao redor de produção industrial, artefatos, ornamentos, burguesia, comércio, valorização estética e simbólica de produtos, valorização do bem-estar individual acima do social. Foram necessários muitos anos para que houvesse uma dissociação de tais ideias arraigadas a um ambiente de luxo e glamour, que ainda não se esmaeceram totalmente.

Assim como a própria profissão, também os designers enfrentam desafios em um primeiro momento para estabelecer-se como profissionais dentro de um mercado de trabalho que cresce, mas que oficialmente ainda não reconhece a importância do profissional, haja vista a demora verificada no processo de regulamentação e reconhecimento da profissão, uma conquista que parece estar ligada ao valor que se atribui á industrialização de um país. Outro desafio enfrentado pelos profissionais é a constante e equivocada associação do design à produção de artefatos de luxo, o que por vezes insere os designers em complexas situações nas quais precisam comprovar que a profissão não se resume a luxo e alto valor. Sobre a presença do conceito de luxo como um componente da valorização individualizada da atualidade, pela qual por vezes o design é tomado, Almeida e Batista (2005) inferem:

Partimos do pressuposto de que a ideologia liberal valoriza prerrogativas individuais em contraposição a direitos sociais. [...] A realização dessas prerrogativas confunde-se com o ato de consumir. O direito à cidadania se reduz à possibilidade do consumo de bens. Sob essa ótica, o poder aquisitivo converte-se em virtude, posto que proporcione a compra de bens e de serviços inacessíveis à grande parte da população mundial. Tal prerrogativa será descrita por Benjamin Constant no início do século XIX como liberdade dos modernos. (ALMEIDA; BATISTA, 2005, p. 2). Os autores reforçam o valor do luxo e da individualidade ao se expressarem da seguinte forma: "Assim, o mercado de luxo encontra fundamentos ideológicos, culturais e morais para se expandir até mesmo em países tomados por sérios problemas sociais" (ALMEIDA; BATISTA, 2005, p. 2). Tais autores relatam que este mercado de luxo é estimulado pela busca de um senso de reconhecimento, liberdade e por uma tendência a considerar que o prazer individual e imediato é o objetivo final da vida, de modo que estes 
impulsos sejam materializados em desejos e como consequência nos produtos constituindo a concepção de que o design é sinônimo de luxo.

Atualmente ainda há um culto à individualidade e à exclusividade. Diante do lançamento de novos produtos cujo acesso se faz restrito ás camadas elitistas, por motivos relacionados ao poder aquisitivo, quando estes produtos se tornam acessíveis às camadas mais populares, elites se consideram niveladas com aqueles por elas vistos como inferiores e exigem, de modo mais velado, produtos que os diferenciem novamente. Mais uma vez o design entra em cena como diferenciador e seguidor de regras ao mesmo tempo em que cultua o individual, o luxo, a elite, se afastando do social - o que não significa sobremaneira que o design não trabalhe para o social. Assim, dificulta-se novamente a dissociação da visão direcionada ao design relacionado ao consumo de luxo.

No que tange à realidade brasileira, tal visão do design como produto de luxo é fortalecida pela tendência ao culto da produção europeia - um comportamento existente entre os mais e os menos abastados -, apresentando-se aí outro grande desafio para o designer brasileiro: estabelecer-se como um profissional respeitado e criador de uma produção original e qualitativa. O design não caminha com plena liberdade, segue regras sociais, porém estas regras ainda se fundamentam no individual.

É no plano individual também que operam outros obstáculos para o designer enquanto profissional: o reconhecimento de sua importância dentro das empresas nas quais atuam. De acordo com Phillips (2008) por vezes no desenvolvimento de um projeto, as decisões centrais são tomadas pelos profissionais de outras áreas, aos quais o autor se refere como "não designers". Segundo o autor, tais atores "[...] geralmente admitem que os designers sejam competentes em produzir soluções estéticas, mas não acreditam que os designers possam pensar e atuar estrategicamente, apresentando soluções adequadas às necessidades dos negócios." (2008, p.94).

Assim, apresentam-se aos designers também o desafio de adquirir credibilidade e confiança dos seus colegas não designers, o que por vezes transforma-se em uma tarefa desestimulante e estressante. Partindo do princípio de que o design - dado seu caráter interdisciplinar por definição - deveria ser o elemento aglutinador das demais áreas envolvidas no projeto, o que se verifica são profissionais que lutam dia-a-dia para provar seu valor, como ressalta Phillips (2008).

Os designers costumam enfrentar muitos obstáculos durante seu trabalho. Em primeiro lugar, porque devem propor soluções inovadoras, que não são facilmente aceitas, pois quase sempre sofrem resistências. Em segundo lugar, porque não conseguem obter os recursos e apoios necessários, devido ao seu baixo prestígio dentro das empresas. Muitos designers e gerentes de design 
sentem-se desanimados diante desses obstáculos. Eles dizem que gostariam de ter um prestígio semelhante ao de outras funções na empresa. (PHILLIPS, 2008, p.153).

A falta do reconhecimento profissional dentro das empresas é fato alarmante, uma vez que em um mercado competitivo global, no qual as tecnologias se equiparam de maneira veloz, cabe ao designer à criação e o desenvolvimento de produtos diferenciados e competitivos o qual, segundo Landim (2010), é de suma importância que participe das definições estratégicas de uma empresa desde o início.

Para ser usado de modo estratégico, o design deve participar das definições estratégicas a partir de nível decisório mais alto e integrado com todas as áreas relevantes. O design estratégico materializa-se quando o importante é desenvolver o produto certo - ter "eficácia do processo de design", e não somente desenvolver corretamente o produto, tendo "eficiência no processo de design". (LANDim, 2010, p.27 - 28).

Em uma perspectiva mais ampla, além do reconhecimento dentro do mercado de trabalho, também se faz necessário o reconhecimento perante a sociedade e às políticas públicas e trabalhistas. Neste cenário, a regulamentação profissional é outro assunto espinhoso. Neste quesito deveriam ficar explícitas, segundo relatos de Braga (2005) questões sobre código de ética e mercado de trabalho, remuneração profissional, a formação do desenhista industrial, órgãos fiscalizadores, registros e proteção de profissionais, demais questões diretamente ligadas ao interesse do profissional. Um caminho que tem se deparado com extremas dificuldades também no Brasil, pois envolve desavenças inclusive políticas, como mencionadas por Marcos da Costa Braga, Doutor em história social: O deputado Marcelo Cerqueira foi convidado para auxiliar na revisão do anteprojeto aprovado no $1^{\circ}$ ENDI, e no seu encaminhamento como substitutivo ao Congresso Nacional. Entendia-se na época que este era o melhor caminho, já que a "tramitação de dois projetos atrasaria o processo, principalmente sendo apresentados por parlamentares de partidos opostos". (BRAGA, 2005, p. 4).

Braga apresenta uma visão muito importante sobre o ser designer, como indivíduo social apresentado no seguinte relato de sua autoria, digno de apreciação:

Joaquim Redig considera que, depois de formados, os designers cariocas [...] buscavam uma entidade profissional que tivesse uma identidade forte do design formada a partir da passagem pela primeira escola superior específica em Desenho Industrial. Por sua vez, Valéria London destaca outra dimensão da questão da identidade, que seria o reconhecimento social de quem seria 
o desenhista industrial em meio à presença de vários profissionais com diferentes formações e com diferentes níveis de qualidade no exercício do design. O que Valéria London está considerando, em nosso entender, é a identidade social, derivada da identidade profissional, e de seu papel na sociedade. Está colocado aqui o problema do reconhecimento ou identificação, pelo meio social, de quem é o profissional, que atribuições possui, que papel social the foi reservado e quem estaria apto a exercer o desenho industrial. Ser desenhista industrial significaria atuar e optar pela construção de um papel social que envolveria os aspectos éticos e morais internalizados durante a formação acadêmica e a crítica sobre a atuação de 'pares'. Esta construção do ser designer é parte da construção do 'eu' social da pessoa. (Braga, 2005, p. 5).

Desta forma, regulamentar a profissão não seria apenas garantir direitos ao profissional, mas antes apresentá-lo e identificá-lo junto à sociedade, a qual fez do vocábulo design um termo extremamente popular nos últimos anos, sem muitas vezes sequer conhecer seu real significado, quais suas atribuições e principalmente a importância de sua ação.

\section{Considerações finais}

O designer contemporâneo ainda se encontra permeado por valores construídos no passado, como aqueles que referenciam a profissão ao luxo, ao glamour, á beleza, estética, simbolismo apenas. Há vertentes que o dissociam dessa imagem burlesca como o design inclusivo, os aspectos voltados á sustentabilidade, demais questões direcionadas á responsabilidade social, mas os aspectos voltados ao luxo, ao burguês, à moda ainda são muito fortes.

Hoje o design está compondo o meio social como parte inseparável do bem-estar social, mas esta visão ainda não é universal, o que se constitui como uma grande barreira classificada como social. O design contemporâneo tem como principal quesito a questão da responsabilidade social, mas o seu principal público alvo não o reconhece como tal.

A regulamentação da profissão seria uma importante conquista, pois a falta dela compõe com muitos outros equívocos abordados neste estudo como grandes responsáveis pela banalização do termo design e desvalorização profissional. Tal banalização não se restringe somente ao termo, pois este se encontra impregnado de valores ao representar no limite mais do que simplesmente uma categoria profissional, antes representa um ser, uma identidade 
social construída no ser designer. Assim, quando se banaliza o termo logo se banaliza este ser social.

Ainda restam muitas barreiras a vencer, e o design como uma profissão que pode ser considerada nova quando comparada às demais, ainda se apresenta em fase de construção. Portanto, não se sabe quais obstáculos ainda serão enfrentados, entretanto, pode-se afirmar com base na história da própria profissão e dos próprios profissionais que o campo do design, por refletir como poucas áreas as mudanças sociais, continuará a se adaptar a estas, caminhando - mesmo que por vezes timidamente - a grandes conquistas, transpondo obstáculos e se firmando como uma das mais valorosas áreas do saber humano.

\section{Referências bibliográficas}

ALMEIDA, R. R.; BATISTA, W. B. Desenho Industrial e consumo de luxo. In: Congresso Internacional de Pesquisa em Design, 3, 2005, Rio de Janeiro, 12 á 15 de outubro. 2005. Anais do III Congresso Internacional de Pesquisa em Design. Rio de Janeiro: ANPED.

BRAGA, M. DA C. Regulamentação da Profissão de Desenho Industrial: os primeiros passos de uma 'bandeira'. In: Congresso Internacional de Pesquisa em Design, 3, 2005, Rio de Janeiro, 12 á 15 de outubro. 2005. Anais do III Congresso Internacional de Pesquisa em Design. Rio de Janeiro: ANPED.

CARDOSO, R. Uma introdução à história do design. $2^{\text {a }}$ Ed. São Paulo: Editora Blucher, 2004.

FORTY, A. Objetos de desejo - design e sociedade desde 1750. Tradução Pedro Maia Soares. São Paulo. Cosac Naify, 2007.

HESKETT, J. Desenho Industrial. Tradução Fábio Fernandes. $3^{\text {a }}$ ed. Rio de Janeiro: José Olympio, 2006.

LANDIM, P. DA C. Design, empresa, sociedade. São Paulo: Cultura Acadêmica Editora. 2010.

LÖBACH, B. Design Industrial - Bases para a configuração de produtos industriais. Tradução Freddy Van Camp. São Paulo: Editora Blucher, 2001. 
MOTA, M. J. DA; MARTINS, A. P.; SILVA, J. C. P. DA; NASCIMENTO, R. A. DO. Design Contemporâneo: um resgate histórico e as influências para a sua formação. In: Congresso Internacional de Pesquisa em Design, 4, 2007, Rio de Janeiro, 11 a 13 de outubro. 2007. Anais do IV Congresso Internacional de Pesquisa em Design. Rio de Janeiro: ANPED.

PHILLIPS, P. L. Briefing: A gestão do projeto de design. São Paulo: Editora Blucher, 2008. 
Recebido em: $15 / 03 / 2013$

Aceito em: 01/05/2013

\section{Como citar}

MARTINS, E. ; PIZARRO, C. V. ; SILVA, J. C. P. ; PASCHOARELLI, L. C. O papel do designer contemporâneo a partir das contribuições europeias na formação profissional. Arcos Design. Rio de Janeiro: PPD ESDI - UERJ. Volume 7 Número 1 Junho 2013. pp. 138-156. Disponível em: [http://www.e-publicacoes.uerj.br/index.php/ arcosdesign]

DOI

10.12957/arcosdesign.2013.10000

\section{(c) (i) (2)}

A Revista Arcos Design está licenciada sob uma licença Creative Commons Atribuição - Não Comercial - Compartilha Igual 3.0 Não Adaptada. 